\title{
Socio-Economic Status and Communicational Characteristics of Farmers Using Bio-Control Agents
}

\author{
Rewendra Kumar Sahu ${ }^{1 *}$, M. L. Sharma ${ }^{2}$, P. Mooventhan ${ }^{3}$ and M.A. Khan ${ }^{4}$ \\ ${ }^{1}$ Department of Agricultural Extension, College of Agriculture, Indira Gandhi Krishi \\ Vishwavidyalaya, Raipur, Chhattisgarh, 492012, India \\ ${ }^{2}$ Pt. Kishori Lal Shukla College of Horticulture \& Research Station, Rajnandgaon, \\ Chhattisgarh, 491441, India \\ ${ }^{3}$ ICAR- National Institute of Biotic Stress Management (ICAR-NIBSM), Baronda, Raipur, \\ Chhattisgarh, 493225, India \\ ${ }^{4}$ Department of Agricultural Extension, College of Agriculture, Indira Gandhi Krishi \\ Vishwavidyalaya, Raipur, Chhattisgarh, 492012, India \\ *Corresponding author
}

\section{A B S T R A C T}

\begin{tabular}{|l|}
\hline Key w or d s \\
Bio-control agents, \\
Socio-economic \\
status, \\
Communicational \\
characteristics
\end{tabular}

\begin{abstract}
Bio-control agents are an important component of integrated pest management and help to counteract insecticide resistant pests, withdrawal of chemicals and minimize the usage of pesticides. Although the adoption of Bio-control agents is strongly affected by the socioeconomic environment in which they are to be applied and by farmers' attitudes, these factors have been poorly investigated in bio-control agent's research and development programs. The main purpose of this study is to examine the socio-economic status and communicational characteristics of farmers using bio-control agents in Chhattisgarh plains zone. Face to face interviews of 200 respondents was conducted to collect the data for the study. Purposively sampling method was used to collect data from farmers of study area. The results showed that 43.00 per cent of the respondents were marginal farmers (Below $1.0 \mathrm{ha})$ and majority $(36.40 \%$ ) has agriculture only as their sole occupations however only about one-third $(32.50 \%)$ of the respondents were at the income range upto ₹ 50,000. In mass media exposure and extension contact farmers using bio-control agents were found under medium level categories.
\end{abstract}

\section{Introduction}

Adoption of new farm technology is very crucial for agriculture productivity and development. Farmer's perception of new agricultural technology influences their decision to adopt the same. The development of agriculture has much to do with the economic welfare of our country and it's totally based on the agrochemicals products. There are various environmental effects due to agrochemicals have created worldwide concern. Now, the approach is to shift from chemical methods to non-chemical methods 
for enhancing soil fertility and dealing pests. The alternatives are very expensive and not yet in widespread use. However, Bio-control is effective and economical in nature. BioControl agents are environmentally safe, nontoxic and non-polluting. Biological control agents are pest-specific and greatly prefer to feed on the target organism, leaving non-pest organisms undisturbed. Once a biological control program is underway, the field aspects of the program are inexpensive compared to other control methods and require little human efforts. Biological control agents can sustain themselves and spread on their own. Beneficial animals and plants as well as people in an area where biological control is being used are unaffected by this method of control (Randhawa, 2015). Through the use of bio-control agents, help to counteract insecticide resistant pests, withdrawal of chemicals, minimize the usage of pesticides, healthy plants can be grown, while enhancing the sustainability and the health of the soil. The main problem was low level of adoption regarding bio-control agents in present situation. So that to increase the level of adaptation and awareness among the farmers the extension worker must understand the socio-economic status and communicational characteristics of farmers.

\section{Materials and Methods}

The study was carried out in Chhattisgarh. Out of 15 districts in Chhattisgarh plain zone, the study was undertaken in 4 districts randomly i.e. Raipur, Durg, Dhamtari and Rajnandgaon. Two villages from each selected district were identified for investigation purposively, where most farmers were using bio-control agents in their crop. In this way a total eight villages (2 $\mathrm{X} 4=8$ ) was taken for the study. Each village is considered as one group and total 8 groups were undertaken. The respondents were the farmers who are using the bio-control agents in their crop. Total 25 farmers were selected purposively from each selected village, in this way a total of 200 farmers (Total $25 \times 8=$ 200) were selected for the survey considered as per the scheduled design for the study. The major criterion considered for the selection of farm technology was that it should be new and need based one. Accordingly, "bio-control agents" was selected. Data were collected from April, 2018 to February, 2019. For studying various socio-economic and communicational characteristics of farmers using bio-control agents, the respondents were interviewed by structured interview schedule by researcher. The data were analyzed with the help of suitable statistical measures they are as follow:

\section{Frequency}

A frequency is the number of times a data value occurs in an experiment or study.

\section{Percentage}

Percentages were calculated in simple and cross tables for the purpose of comparisons; $\mathrm{F}$ / $\mathrm{n} \times 100$. Where $\mathrm{F}$ represents the class frequency and $\mathrm{n}$ stands for total respondents.

\section{Mean}

The mean or average that is used to derive the central tendency of the data in question. It is determined by adding all the data points in a population and then dividing the total by the number of points. The resulting number is known as the mean or the average.

\section{Standard deviation}

Standard deviation is the measure of dispersion of a set of data from its mean. It measures the absolute variability of a distribution; the higher the dispersion or variability, the greater is the standard deviation and greater will be the magnitude of 
the deviation of the value from their mean.

\section{Results and Discussion}

\section{Socio-economic characteristics}

\section{Occupation}

Occupational status decides the extent of involvement of a farmer in farm operations. Agriculture as a full time occupation makes an individual to allocate more time in farming. The results on the distribution of farmers under different categories with respect to their occupational status are presented in Table 1. It is observed that majority $(36.40 \%)$ of the respondents has agriculture only as their sole occupations, followed by 26.78 per cent with Agriculture + Labour, about 20.08 per cent with Agriculture + Animal husbandry and the remaining 9.62, 6.69 and 00.42 per cent with Agriculture + Business, Agriculture + Service and Agriculture + others services, respectively.

Agriculture is counted as the chief economic occupation of the state. Agricultural labour and animal husbandry also engaged the major share of the total population of the state. About 80 per cent of the population of the state is rural and their main livelihood is solely depended on agriculture and agriculture-based sub sectors.

\section{Annual income}

Income is a very important variable which makes the farmers enable to adopt a scientific innovations which leads to increase farm production and ultimately improve the standard of living.

The data from a Table 1 indicated that about one-third $(32.50 \%)$ of the respondents were at the income range upto ₹ 50,000 followed by 27.00 per cent of farmers earning ₹ $1,00,001$ to 2, 00,000. Further, it could be observed from the same Table that 26.00 per cent of farmers were under the income range between ₹ 50,001 to $1,00,000$ while $₹ 2,00,001$ to $5,00,000$ incomes were earned by 13.50 per cent farmers and least percentage $(1.00 \%)$ of the respondents had obtained above ₹ 5, 00,000 as an annual income from farming and allied activities. It is inferred from the results that majority $(32.50 \%)$ of the farmers had their earning up to ₹ 50000 per year. The trend of above data may be that most of farmers are depending on agriculture as a sole occupation and major source of income for their livelihood.

The poverty level in Chhattisgarh is very high. The prevalence of poverty in the rural and urban areas is almost the same. Causes of poverty are changing trends in a state economy associated with the lack of education, overpopulation, illiteracy and natural problems like of rainfall, drought and flood etc. Low level of income among farmers is a matter of serious concern in the state.

\section{Land holding}

The respondents were classified in to five groups according to their land holding namely, marginal farmers (Below 1.0 ha), small farmers (1.1 to 2 ha), semi medium farmers (2.1 to 4 ha), medium farmers (4.1 to 10.0 ha) and big farmers (above $10.00 \mathrm{ha}$ ). The size wise distribution of the farmers is furnished in Table 1.

The data revealed that 43.00 per cent of the respondents were marginal farmers (Below 1.0 ha) followed by 21.50 per cent respondents has small size of land holding (1.1 to $2 \mathrm{ha}$ ) and 18.50 percent respondents has semi medium (2.1 to $4 \mathrm{ha}$ ) land holding. It was found that 16.00 and 1.00 per cent of the respondents had medium (4.1 to $10.0 \mathrm{ha}$ ) and large size of land holding (above $10 \mathrm{ha}$ ), respectively. 
Based on the findings it can conclude that most of the respondents were marginal and small farmers may be due to transfer of ownership from parents to subsequent progeny in the family which allow the fragmentation of land.

\section{Communicational characteristics}

\section{Mass media exposure}

Media play an important role in effective dissemination of the farm knowledge. In general, agriculture, animal husbandry, fishery, forestry etc information are spread through magazines, newspapers, radio and television besides the modern gadgets like mobile phone and internet.

Hence, it becomes necessary to know about the level of media participation of the respondents. The classification of respondents based on their level of mass media exposure and the corresponding frequency distribution is presented in Table 2 .

It has been observed that majority $(99.00 \%)$ of the farmer's posse's television and mobile phone followed by newspaper $(62.00 \%)$, radio $(49.50 \%)$, internet $(36.50 \%)$, computer $(15.50 \%)$ and magazine $(3.00 \%)$ at home. Here, 99.00 per cent of the farmers using mobile phones, it showed the positive mind setup of the farmers using bio-control agents towards ICTs gadgets. Further, mass media usage analysis revealed that 93.00 per cent of the respondents using mobile phones daily, followed by watching television $(92.00 \%)$, reading newspaper $(32.00 \%)$, internet $(23.50 \%)$, listening radio $(15.00 \%)$, using computer daily $(05.50 \%)$ and magazine reader $(00.50 \%)$. It is very critical to observe that majority $(84.50 \%)$ of the respondents never used computer and 63.50 per cent does not use the internet. It may be due to their poverty, poor infrastructure and unaffordable nature of living and unable to invest money in internet/computer. On the other hand, farm magazine is unreachable to homes of 97.00 per cent of farmers at their doorsteps (Fig. 1).

Data from Table 3 revealed that 66.50 per cent of farmers using bio-control agents were medium level of mass media exposure, while 23.50 per cents respondents were low level of mass media exposure and 10.00 per cent of respondents were found high level mass media exposure. The reason behind the less percentage in high-level mass media exposure might be because of their age, 68.50 per cent of respondents were found aged above 36 years. As they get older the connectivity with mass media decrease, simultaneously.

\section{Extension contact}

Regarding extension contact of the respondents, Table 4 revealed that cent per cent $(100.00 \%)$ respondents were contacted with RAEOs /RHEOs in which 82.50 per cent of the respondents regularly contacted to RAEOs /RHEOs and remaining 17.50 per cent of the respondents occasionally contacted to RAEOs /RHEOs. While, 70.50 per cent respondents were contacted to SADOs/ SHDOs in which only 2.00 per cent respondents regularly contacted while more than two-third $(68.50 \%)$ of the respondents occasionally contacted and remaining 29.50 per cent never contacted to SADOs/ SHDOs.

Moreover data incorporated that 67.00 per cent of the respondents contacted to Kissan call centre (KCC) among them one-fifth $(19.50 \%)$ of the respondents contacted regularly, 47.50 per cent occasionally and remaining one-third $(33.00 \%)$ of the respondents never contacted to kissan call centres. Whereas, 60.00 per cent of the respondents contacted to SMS of KVK's among them 18.00 per cent of the respondents were regularly contacted, 42.00 per cent were occasionally and remaining 40.00 per cent were never contacted to SMS. 
Table.1 Distribution of the respondents according to their socio-economic

\begin{tabular}{|c|c|c|c|}
\hline Sl. No. & Particulars & Frequency & Percentage \\
\hline \multicolumn{4}{|c|}{ 1. Occupation* } \\
\hline 1. & Agriculture Only & 87 & 36.40 \\
\hline 2. & Agriculture + Labour & 64 & 26.78 \\
\hline 3. & Agriculture + Animal husbandry & 48 & 20.08 \\
\hline 4. & Agriculture + Business & 23 & 9.62 \\
\hline 5. & Agriculture + Service & 16 & 6.69 \\
\hline 6. & Agriculture + others & 1 & 0.42 \\
\hline \multicolumn{4}{|c|}{ 2. Annual family income } \\
\hline 1. & Upto ₹ 50000 & 65 & 32.50 \\
\hline 2. & $₹ 50,001$ to $1,00,000$ & 52 & 26.00 \\
\hline 3. & $₹ 1,00,001$ to $2,00,000$ & 54 & 27.00 \\
\hline 4. & $₹ 2,00,001$ to $5,00,000$ & 27 & 13.50 \\
\hline 5. & Above ₹ 5,00,000 & 2 & 1.00 \\
\hline \multicolumn{4}{|c|}{ 3. Land holding } \\
\hline 1. & Marginal farmer (Below $1.0 \mathrm{ha}$ ) & 86 & 43.00 \\
\hline 2. & Small (1.1 to 2 ha ) & 43 & 21.50 \\
\hline 3. & Semi medium ( 2.1 to 4 ha) & 37 & 18.50 \\
\hline 4. & Medium (4.1 to 10.0 ha) & 32 & 16.00 \\
\hline 5. & Big (Above $10.0 \mathrm{ha}$ ) & 2 & 1.00 \\
\hline
\end{tabular}

*Note: Data are based on multiple responses

Table.2 Distribution of respondents according to their mass media exposure

\begin{tabular}{|c|c|c|c|c|c|c|c|c|c|}
\hline \multirow[t]{3}{*}{ Sl. No. } & \multirow[t]{3}{*}{ Mass media } & \multicolumn{4}{|c|}{ Availability at home } & \multicolumn{4}{|c|}{ Extent of use } \\
\hline & & \multicolumn{2}{|c|}{ Yes } & \multicolumn{2}{|c|}{ No } & \multicolumn{2}{|c|}{ Daily } & \multicolumn{2}{|c|}{ Occasionally } \\
\hline & & $\mathbf{F}$ & $\%$ & $\mathbf{F}$ & $\%$ & $\mathbf{F}$ & $\%$ & $\mathbf{F}$ & $\%$ \\
\hline 1. & News paper & 124 & 62.00 & 76 & 38.00 & 64 & 32.00 & 60 & 30.00 \\
\hline 2. & Radio & 99 & 49.50 & 101 & 50.50 & 30 & 15.00 & 69 & 34.50 \\
\hline 3. & Television & 198 & 99.00 & 2 & 1.00 & 184 & 92.00 & 14 & 7.00 \\
\hline 4. & Mobile phone & 198 & 99.00 & 2 & 1.00 & 186 & 93.00 & 12 & 06.00 \\
\hline 5. & Computer & 31 & 15.50 & 169 & 84.50 & 11 & 5.50 & 20 & 10.00 \\
\hline 6. & Internet & 73 & 36.50 & 127 & 63.50 & 47 & 23.50 & 26 & 13.00 \\
\hline 7. & Others (farm magazine) & 6 & 3.00 & 194 & 97.00 & 1 & 0.50 & 5 & 2.50 \\
\hline
\end{tabular}

Note: Data are based on multiple responses, $\mathrm{F}=$ frequency, $\%=$ percentage

Table.3 Distribution of respondents according to their overall level of mass media

\begin{tabular}{|c|l|c|c|}
\hline Sl. No. & \multicolumn{1}{|c|}{ Level of mass media exposure } & Frequency & Percentage \\
\hline 1. & Low level (Up to 2.34 score) & 47 & 23.50 \\
\hline 2. & Medium level (2.35 -4.94 score) & 133 & 66.50 \\
\hline 3. & High level (Above 4.95 score) & 20 & 10.00 \\
\hline & & \multicolumn{2}{c|}{ Mean $=\mathbf{3 . 6 4}, \mathbf{S D}=\mathbf{1 . 3 0}$} \\
\hline
\end{tabular}


Table.4 Distribution of the respondents according to different types of extension contact

\begin{tabular}{|c|c|c|c|c|c|c|c|c|}
\hline \multirow{2}{*}{$\begin{array}{l}\text { Sl. } \\
\text { No. }\end{array}$} & \multirow[t]{2}{*}{ Extension contacts } & \multicolumn{2}{|c|}{ Regular } & \multicolumn{2}{|c|}{ Occasional } & \multicolumn{2}{|c|}{ Never } & \multirow{2}{*}{$\begin{array}{l}\text { Extent of } \\
\text { contact }\end{array}$} \\
\hline & & $\mathbf{F}$ & $\%$ & $\mathbf{F}$ & $\%$ & $\mathbf{F}$ & $\%$ & \\
\hline 1. & RAEOs/ RHEOs & 165 & 82.50 & 35 & 17.50 & 0 & 0.00 & 91.25 \\
\hline 2. & SADOs/ SHDOs & 4 & 2.00 & 137 & 68.50 & 59 & 29.50 & 36.25 \\
\hline 3. & ADA/ ADH & 0 & 0.00 & 44 & 22.00 & 156 & 78.00 & 11.00 \\
\hline 4. & Kissan call centre & 39 & 19.50 & 95 & 47.50 & 66 & 33.00 & 43.25 \\
\hline 5. & $\begin{array}{l}\text { Scientists of Agricultural } \\
\text { Universities }\end{array}$ & 4 & 2.00 & 60 & 30.00 & 136 & 68.00 & 17.00 \\
\hline 6. & SMS's of KVK's & 36 & 18.00 & 84 & 42.00 & 80 & 40.00 & 39.00 \\
\hline 7. & Officials of NGO's & 7 & 3.50 & 39 & 19.50 & 154 & 77.00 & 13.25 \\
\hline 8. & Officials of private company & 11 & 5.50 & 89 & 44.50 & 100 & 50.00 & 27.75 \\
\hline 9. & Bank Officials & 6 & 3.00 & 99 & 49.50 & 95 & 47.50 & 27.25 \\
\hline 10. & Any other (specify) & 0 & 0.00 & 2 & 1.00 & 198 & 99.00 & 0.50 \\
\hline
\end{tabular}

Note: Data are based on multiple responses of time, $\mathrm{F}=$ frequency, $\%=$ percentage

Table.5 Distribution of respondents according to their overall level of extension contact

\begin{tabular}{|c|l|c|c|}
\hline SI. No. & \multicolumn{1}{|c|}{ Level of extension contact } & Frequency & Percentage \\
\hline 1. & Low level (Up to 2.91 score) & 53 & 26.50 \\
\hline 2. & Medium level (2.92-6.64 score) & 130 & 65.00 \\
\hline 3. & High level (Above 6.65 score) & 17 & 8.50 \\
\hline & & & Mean $=\mathbf{4 . 7 8 , ~ S D ~}=\mathbf{1 . 8 7}$ \\
\hline
\end{tabular}

Fig.1 Distribution of respondents according to their mass media exposure

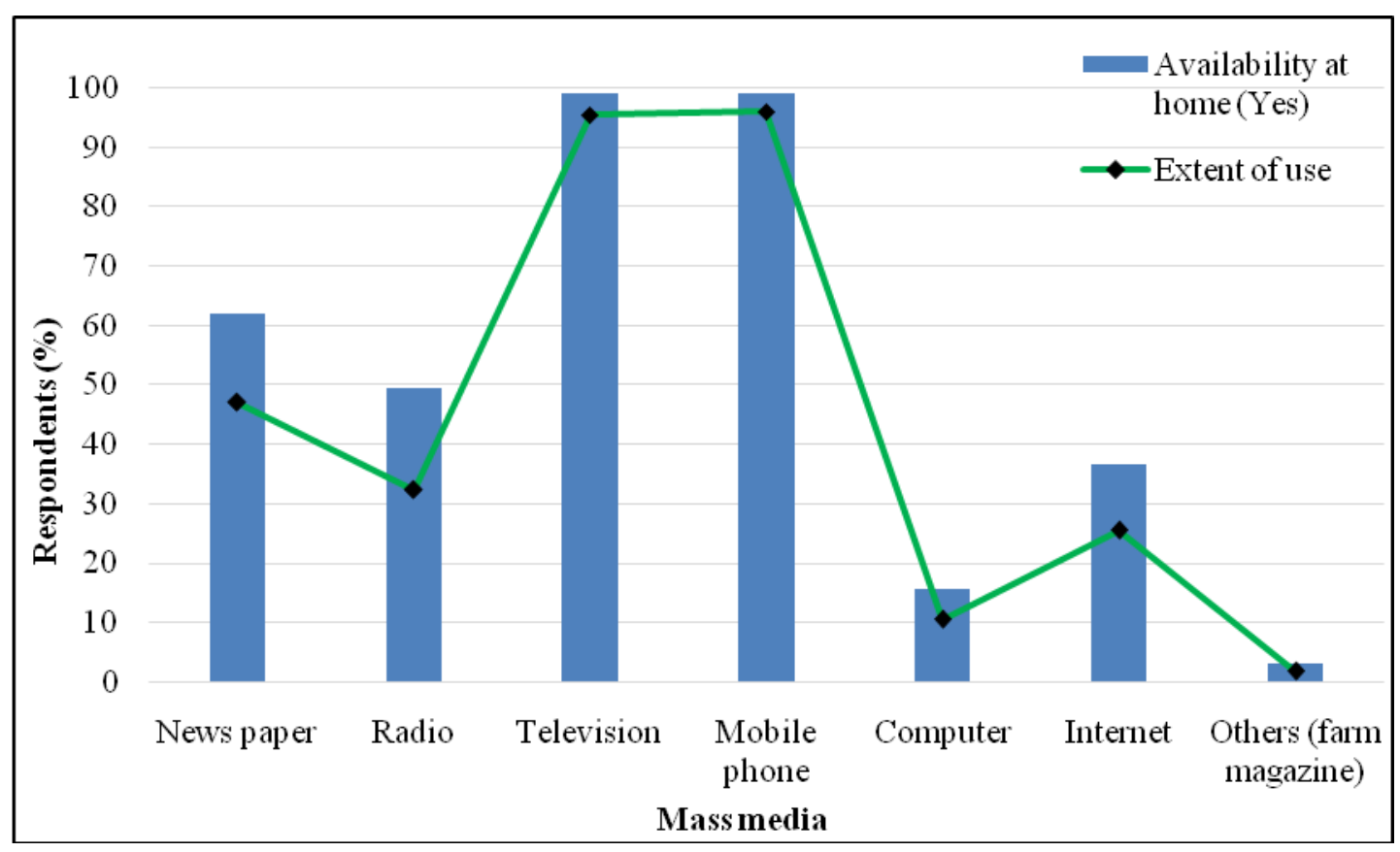


Fig.2 Distribution of the respondents according to different types of extension contact

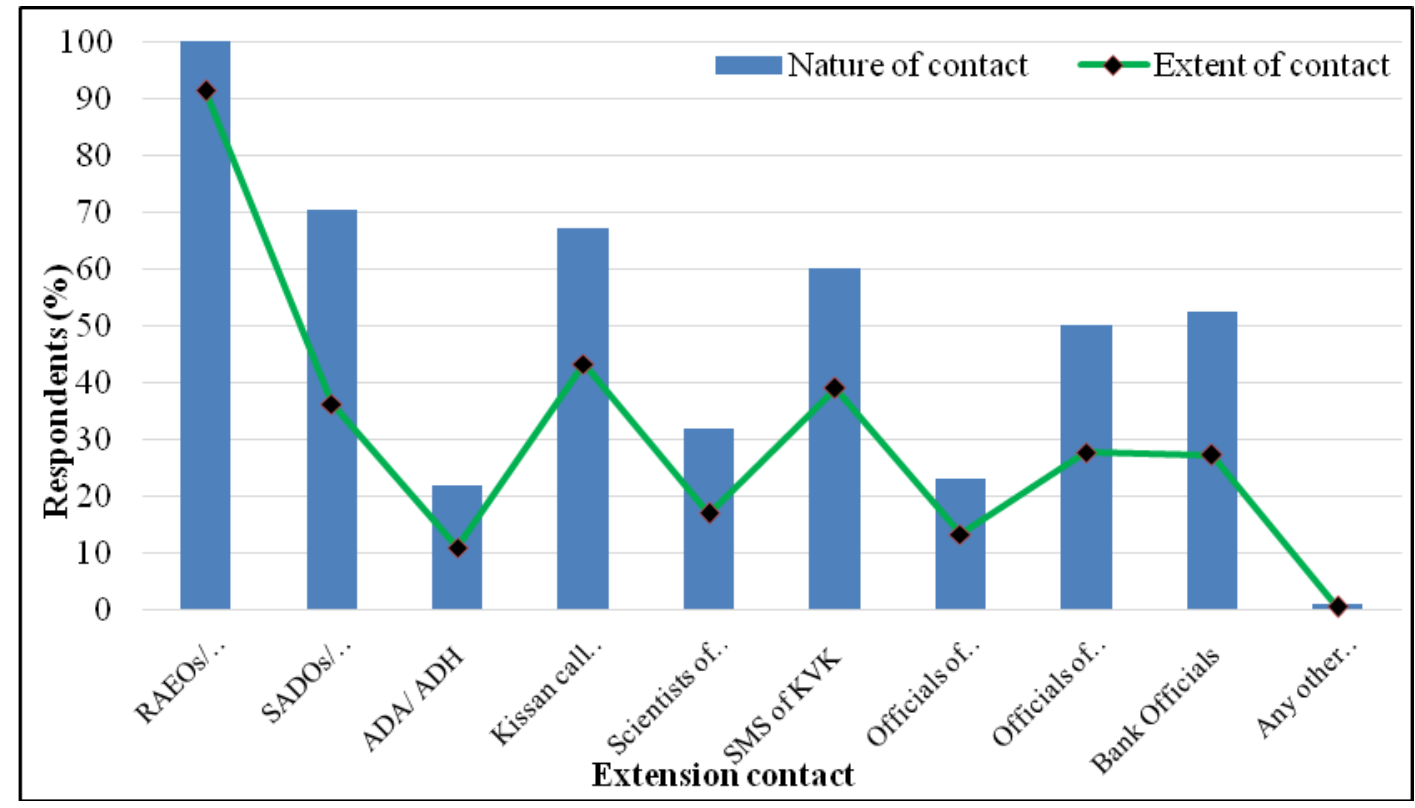

While 52.50, 50.00, 32.00, 23.00 and 22.00 per cent respondents contacted to bank officials, extension personnel of private company, scientists of agricultural universities, development officers of NGOs and $\mathrm{ADA} / \mathrm{ADH}$, respectively, as per their convenience. At last, we found that negligible $(1.00 \%)$ per cent of the respondents were contacting with other source.

Regarding extension contact, the data explained that the highest respondents contacted with rural agriculture extension officers (RAEOs)/ rural horticulture extension officers (RHEOs) followed by senior agriculture development officers (SADOs)/ senior horticulture development officers (SHDOs), Kissan call centre and subject matter specialist (SMS) of krishi vigyan kendra (KVK). The reason behind the highest contact with rural agriculture extension officers (RAEOs) because they are working at village level and visited the village regularly, hence good rapport builds between respondents and RAEOs was developed. Similarly, Painkara (2018) indicated that highest $(98.75 \%)$ respondents contacted with
RAEOs followed by second highest (31.88\%) respondents contacted to SADOs (Fig. 2).

The data regarding overall level of extension contact with extension personnel given in Table 5 revealed that out of three categories, the highest $(65.00 \%)$ respondents had medium level of contact with extension personnel followed by 26.50 per cent of the respondents were low contacted with extension personnel and only 8.50 per cent of the respondents were high level contacted with extension personnel. It indicates that extension personnel working at village level had medium contact regarding agriculture works.

It is concluded from above table that most of them were marginal farmers and has agriculture only as their sole occupations whereas, their income range upto ₹ 50,000. They have medium mass media exposure and extension contact. There was lack of awareness among farmers regarding knowledge of bio-control agents, followed by lack awareness among farmers regarding use of bio-control agents and non-availability of 
bio-control agents. Also the study suggests that there is a need of government assistance to promote the use of bio-control agents in crops. It is clear from the discussion with farmers that they want to be trained on various bio-control practices. This finding shows that the government can still play an important role in improving the adoption of bio-control agents and consequently increasing the productivity and production of major crops in the study area.

\section{References}

Anandaraja, N. 2002. Developing farmer friendly interactive multimedia compact disc and testing its effectiveness in transfer of farm technology. Ph.D. Thesis, TNAU, Coimbatore.

Manjunath, L. and Balasubramanya. 2002. Effectiveness of Kannada farm magazines as related to readers characteristics, Karnataka Journal of Agricultural Sciences, 15 (4):737-739.

Mankar, D.M., Sawant, V.Y. and Sahustrabudha, A.G. 2000. Socio economic and psychological profile of fisherman. Maharashtra Journal of Extension Education, 19: 159 -163.

Mooventhan, P. 2016. Empowerment of tribal farmers for good dairy farming practices through multimedia approach, Ph.D. Thesis, NDRI, Karnal, Haryana, India.

Painkra, V.K. 2018. Study on diffusion pathway and adoption dimensions of newly released rice varieties in Chhattisgarh plains, Ph.D. (Ag.) thesis, Indira Gandhi Krishi Vishwavidyalaya,
Raipur (C.G.)

Painkra, V.K. 2018. Study on diffusion pathway and adoption dimensions of newly released rice varieties in Chhattisgarh plains, Ph.D. (Ag.) thesis, Indira Gandhi Krishi Vishwavidyalaya, Raipur (C.G.).

Pathak, A. K. and Christopher, K. 2019. Study of socio-economic condition and constraints faced by the farmers in adoption of Bio fertilizer in Bhadohi district (Uttar Pradesh). Journal of Pharmacognosy and Phytochemistry, 8(2): 1916-1917.

Randhawa, A. A., Mangan, T., Rais, M. N., Solangi, A. W. 2015. Constraints in adoption of biological control in sugarcane crop. Journal of Biology, Agriculture and Healthcare, 5(5): 170175.

Rogers, E.M. and Shoemaker, F.E. 1971. Communication of innovation - A cross cultural approach (2 ${ }^{\text {nd }}$ Edition). New York: The Free Press.

Sandesh, H.M., 2004. A profile study of Kannada farm magazine readers in Karnataka. M. Sc. Thesis, University of Agricultural Science Dharwad, India, p. 46-52.

Senthilkumar, M. 2000. Mass media utilization behaviour of farmers. An Analysis, M.Sc. (Ag.) Thesis, TNAU, Coimbatore.

Shukla, N., Negi, E. A., Singh, A., Kabadwa, B. C., Sharma, R. and Kumar, J. 2019. Present Status and Future Prospects of Bio-Agents in Agriculture. International Journal of Current Microbiology and Applied Sciences, 8(04): 2138-2153.

\section{How to cite this article:}

Rewendra Kumar Sahu, M. L. Sharma, P. Mooventhan and Khan, M.A. 2019. Assessment of Socio-Economic Status and Communicational Characteristics of Farmers Using Bio-Control Agents. Int.J.Curr.Microbiol.App.Sci. 8(12): 2894-2901. doi: https://doi.org/10.20546/ijcmas.2019.812.336 